\title{
PROCESSAMENTO DE ADUBO ORGÂNICO, A PARTIR DE RESÍDUOS DOMÉSTICOS, EM UMA COMUNIDADE RURAL: UMA PROPOSTA ECOLÓGICA E VIÁVEL.
}

\author{
Renata Nautran Dalles e Isabel Ribeiro do Valle Teixeira \\ Laboratório de Organismos e Ecossistemas, Depto de Ciências Biológicas, Centro Universitário da \\ Fundação Educacional Guaxupé, Unifeg. \\ isabelfe@email.fundeg.br; ribeirodovalleteixeira@hotmail.com
}

\section{RESUMO}

As comunidades rurais geralmente não têm acesso aos serviços sanitários comuns nos centros urbanos, como recolhimento do lixo e a sua correta destinação. Uma das formas de se resolver o problema do lixo doméstico nestes locais e ainda trazer boas consequiências para comunidade é a sua transformação em adubo orgânico. Esta pesquisa, realizada em uma propriedade rural, envolveu atividades de educação ambiental, onde foram enfatizadas a redução do uso do lixo inorgânico e a transformação do lixo orgânico. Após esta ação a coleta de lixo orgânico foi estipulada regularmente, juntamente com o desenvolvimento de um processo alternativo de compostagem. Ao longo do processo de compostagem foram analisadas a influência da temperatura e umidade neste processo e o diagnóstico do produto final. Constatou-se, no final de todo este processo, uma mudança de comportamento da população em relação ao seu lixo, que reduziu a quantidade de lixo gerado e que separou o orgânico do inorgânico, além de ter acompanhado todo o processo da transformação deste lixo em um produto viável na adubação agrícola. O processo de compostagem desenvolvido é bem adaptado às condições climáticas da região, não envolve muita mão de obra, tem baixo custo e é de boa qualidade.

Palavras-chave: Sustentabilidade, Reaproveitamento de lixo, adubo orgânico, compostagem, agricultura.

\begin{abstract}
One way to solve the problem of household waste is its transformation into organic fertilizer. This research was conducted on a farm, involving environmental education activities, collection of organic waste, development of an alternative process of composting, analysis of the influence of temperature and humidity and the diagnosis of the final product. We founded a change of behavior of the population, which resulted in the reduction of this and it is possible its transformation into a viable product.
\end{abstract}

Keywords: Sustainability, waste, organic fertilizer, composting, agriculture 


\section{INTRODUÇÃO}

Uma das piores conseqüências do estilo de vida moderno é a enorme quantidade de resíduos produzidos comumente denominados como lixo. Infelizmente as soluções para este problema não são simples e rápidas, pois envolvem diretamente o modo de vida da maioria das civilizações modernas. Dentre as soluções para o lixo está a sua redução e o desenvolvimento de procedimentos sustentáveis para com o lixo produzido inevitavelmente. Para tal, é necessário o desenvolvimento de um bom programa de educação ambiental e desenvolvimento de tecnologias viáveis.

A educação ambiental envolve vários fatores, entre eles ela deve estar adaptada à comunidade em que ela vai ser desenvolvida. A Educação Ambiental no âmbito rural deve transcender a simples lógica do valor agrícola, buscando a responsabilidade ambiental na construção de um mundo que valorize a diversidade biológica e a diferença cultural. Não basta que a Educação Ambiental esteja inserida no âmbito escolar, mais é necessário que esta esteja vinculada às causas, aos desafios, sonhos, a historicidade e a cultura dos povos que vivem no meio rural (REVISTA BRASILEIRA DE EDUCAÇAÕ AMBIENTAL, 2004: 84). No meio rural, as comunidades experimentam condições diferentes das comunidades urbanas, apesar das pessoas destes locais estarem mais próximos ao ambiente natural, elas não tem acesso a serviços comuns das cidades, como a coleta de lixo e o seu correto descarte. A problemática do lixo pode ser um ponto concreto para o desenvolvimento de atividades de educação ambiental este meio. A população local, ao ser conscientizada de todos os aspectos relacionados aos resíduos produzidos por ela, pode mudar seu comportamento e ainda desenvolver soluções adequadas para sua realidade.

\section{Soluções para a problemática do lixo orgânico nas comunidades rurais}

Quando os resíduos produzidos são orgânicos, uma das soluções é transformálos em adubos passíveis de enriquecer os solos cultivados. A compostagem de resíduos alimentares vem crescendo como uma tecnologia alternativa para esta transformação. Esta atividade vem sendo bem difundida, nos Estados Unidos, por exemplo, já existiam em 1999, 100 usinas de compostagem em funcionamento (GLENN \& GOLDSTEIN, 1999). Porém, muitas destas técnicas de transformação se mostram inviáveis, pois utilizam equipamentos caros e/ou são trabalhosas, fazendo com que o agricultor, que geralmente tem pouco acesso a educação ambiental, desista de aplicá-las em um período 
curto de tempo. Dentre os métodos de compostagem, o que se utiliza leira aerada tem sido largamente adotado como um método rápido e fácil (TOUART, 1999; SIKORA \& SULLIVAN, 2000).

Os fertilizantes orgânicos, em contraste com os denominados "químicos" (sintéticos), originam-se de resíduos de plantas ou animais (produtos facilmente encontrados em lixos domésticos) ou de depósitos naturais em rochas. Para que as plantas possam absorver esses nutrientes dos resíduos, os compostos orgânicos precisam ser degradados, o que ocorre normalmente pela ação de microorganismos do solo, em um processo denominado mineralização, que depende de muitos fatores, incluindo temperatura, disponibilidade de água e oxigênio, além de tipo e número de microorganismos presentes no solo (PEREIRA NETO, 1996).

Quando este processo de decomposição microbiana, de oxidação e oxigenação de uma massa heterogênea de matéria orgânica é desenvolvido de uma forma controlada é denominado de compostagem (KIEHL, 1985). Nesse processo ocorre uma aceleração da decomposição aeróbica dos resíduos orgânicos por populações microbianas, pois são oferecidas as condições ideais para que os microorganismos decompositores se desenvolvam (temperatura, umidade, aeração, $\mathrm{pH}$, tipo de compostos orgânicos existentes e tipos de nutrientes disponíveis). Segundo Teixeira et al (2004) a compostagem pode ser definida como um processo de decomposição da matéria orgânica pela ação de fungos, bactérias e outros microorganismos, que agindo em ambiente aeróbio, na presença da água, transformam matéria orgânica em composto orgânico, conhecido e comercializado também como húmus.

A técnica de compostagem a partir de lixo orgânico mais usada é a de leira por revolvimento. Nesta técnica, a decomposição da matéria orgânica é realizada pelo processo aeróbico e a introdução do oxigênio na leira ocorre através do revolvimento periódico da massa de compostagem (PEREIRA NETO \& CUNHA, 1995). No estado do Pará, por exemplo, nos Municípios de Bacarena, Moju, Abaetuba e em IgarapéMirim, estão em funcionamento quatro unidades de reciclagem e compostagem de lixo urbano, instaladas pela empresa Albras - Alumínio Brasileiro S. A, nas quais o processo de compostagem é realizado em leira, por revolvimento manual a cada três dias. Porém, este processo, apesar de eficiente, demanda trabalho diário o que pode encarecer ou mesmo desanimar pequenos agricultores.

A aeração de leiras de compostos é bem discutida por vários autores (veja KIEHL, 1985; PEREIRA NETO, 1996). Vários modelos de equipamentos podem ser 
utilizados em leiras de compostagem para promover a aeração e, conseqüentemente, promover o aumento da temperatura e a aceleração do processo. Dentre estes modelos, o processo de compostagem em leira estática, com aeração natural, apresenta como vantagem não necessitar de revolvimento a cada três dias, na fase de bioestabilização (período pelo qual a matéria alcança o equilíbrio químico). Consequientemente, há redução de mão-de-obra nessa atividade e um uso de menor área de pátio de compostagem. Além disso, incrementa-se em cerca de $30 \%$ a produção de composto orgânico, com o reaproveitamento da mão-de-obra na triagem do lixo orgânico, na unidade de compostagem (TEIXEIRA et al, 2004).

A agricultura e a pecuária produzem grandes quantidades de resíduos orgânicos, como dejetos de animais e restos de culturas, palhas e resíduos agroindustriais, os quais, muitas vezes, provocam grandes problemas de poluição. Muitos desses resíduos são perdidos por não serem coletados e reciclados, ou por serem destruídos pelas queimadas. Todavia, se fossem manipulados adequadamente, poderiam suprir aos sistemas agrícolas uma boa parte da demanda de insumos, sem afetar os recursos do solo e do ambiente (TEIXEIRA et al, 2002).

Além dos resíduos agrícolas, os resíduos sólidos, domésticos produzidos em municípios, cuja população varia de 3 a 15 mil habitantes, caracterizam-se por apresentar alto teor de matéria orgânica, em torno de $50 \%$ a $70 \%$ do total (PEREIRA NETO \& CUNHA, 1995). Em média, cada pessoa adulta produz o equivalente a $600 \mathrm{~g}$ de lixo por dia, correspondendo, em uma cidade de 20 mil habitantes, à produção é de cerca de 12 mil Kg/dia (ALVES, 1998). Em cidades de pequeno porte, estima-se que a quantidade de lixo domiciliar produzida por habitante esteja entre 400 e $600 \mathrm{~g}$ diárias e que nos grandes centros esta quantidade pode chegar a $1,5 \mathrm{Kg} /$ habitante /dia.

Desta forma, a matéria-prima para a produção de um fertilizante agrícola é produzida em grandes quantidades, tanto na agricultura, como no lixo doméstico, porém, esta transformação deve seguir as normas técnicas, sanitárias e qualitativas para comercialização e utilização. A legislação brasileira, que determina que o fertilizante orgânico composto, para ser comercializado, deve apresentar as seguintes garantias: Matéria orgânica: mínimo de $20 \%$, com tolerância de menos $10 \%$. Índice pH: mínimo 6,0 com tolerância de menos $10 \%$. Nitrogênio total: $1,0 \%$ com tolerância de menos 10\%. Relação carbono/nitrogênio: 18/1 com tolerância de até 21/1. Umidade: máximo de $10 \%$ com tolerância de mais $10 \%$. Não deve conter substâncias fitotóxicas, agentes patogênicos e metais pesados acima dos limites toleráveis (Ministério da Agricultura, 
Pecuária e Abastecimento. Instrução Normativa n ${ }^{\circ}$. Brasília: Diário Oficial da União; 2004).

Enfim, a compostagem surge como uma solução ecológica para o problema do lixo, pois é considerada uma forma de reciclagem, já que quase toda a parte orgânica do lixo é aproveitada (CRAVO et al., 1998). A compostagem oferece a vantagem de ser de baixo custo operacional, ter o uso benéfico dos produtos finais na agricultura e diminuir a poluição do ar e das águas subterrâneas. Porém, apesar de todas as vantagens, este processo pode resultar em um composto com metais pesados ou mesmo com o pH inadequado para utilização em adubação agrícola.

Com o objetivo de desenvolver uma proposta viável e ecológica para os resíduos orgânicos domésticos e agropecuários gerados em comunidades rurais, realizamos um trabalho na Fazenda Nobre, em Mococa, SP. Neste trabalho foram desenvolvidas atividades de educação ambiental com os moradores, que resultou na segregação dos materiais do lixo doméstico, a construção de uma leira estática com ventilação natural com produtos reaproveitados do local (material de demolição) e a realização e acompanhamento do processo de compostagem do lixo orgânico gerado na localidade. Após este processo foi feita a análise de como os processos abióticos (Temperatura e Pluviosidade) que interferem na produção do fertilizante e as análises químicas do produto final, bem como a sua performance deste produto como adubo pela análise da germinação de sementes.

\section{O local escolhido para o desenvolvimento do projeto e suas condições}

O projeto foi desenvolvido no município de Mococa, SP, na Unidade de Compostagem e Reciclagem de Lixo Orgânico Fazenda Nobre (latitude 21 28'04" sul e a uma longitude $47^{\circ} 00^{\prime} 17^{\prime \prime}$ oeste), a uma altitude média de 645 metros. A comunidade rural desta fazenda, que conta com oito famílias, foi envolvida integralmente no processo. O terreno escolhido para a formação da leira de compostagem é nivelado e possui ótimas condições de luz natural e é cercado (o que impede o acesso de animais e de pessoas não envolvidas com o experimento).

\section{Educação Ambiental e a produção e manejo do lixo}

Foi desenvolvido na comunidade, durante 3 meses, um programa de educação ambiental, com três palestras, onde foram abordados temas como o problema ambiental do lixo, como reduzir, como reciclá-lo e finalmente, como segregar a parte orgânica das 
demais. A atividade de educação ambiental teve boa resposta da população local e como conseqüência, o lixo orgânico foi armazenado em um recipiente específico pelas sete famílias residentes no local, que atenderam prontamente a este procedimento. Cada família produziu em média 2,10 $\pm 2 \mathrm{Kg}$ /dia de lixo orgânico, contando com sobras de olericultura desenvolvida pelas famílias. Outro material utilizado para a realização da compostagem foi o esterco bovino, com a produção diária de aproximadamente $30 \mathrm{Kg} /$ dia. Toda a comunidade foi convidada para acompanhar o processo de construção da leira aerada, da compostagem dos resíduos e de seus resultados.

\section{Da construção da leira de compostagem à produção do adubo}

Para a obtenção da matéria-prima para a compostagem, os resíduos orgânicos domésticos, resíduos de animais (de gado doméstico - esterco) e restos vegetais (resíduos de poda de jardim coletados semanalmente após toda a limpeza feita na propriedade) foram coletados semanalmente e armazenados em um local adequado para o início da decomposição.

A sobra de compostagem (composto pré-processado), que contém o concentrado de microorganismos decompositores, foi retirada de um composto (produzido pouco antes do início do experimento) pelo método tradicional de leira removível.

A composição da matéria-prima para a evolução da compostagem foi de $30 \%$ de lixo doméstico orgânico, geralmente composto por sobras de alimentos cozidos, casca de frutas e verduras, $30 \%$ de esterco e $40 \%$ de restos vegetais formado por folhas, galhos e material de poda de grama, nas dimensões de 2,5m de largura na base inferior, 1,0m de largura na base superior, altura de $1,20 \mathrm{~m}$ e comprimento de $4,0 \mathrm{~m}$. Ao longo da leira, na parte interna se estende um túnel de ventilação.

O material foi organizado em camadas, até atingir a altura 1,30m.: primeiramente foi distribuída uma camada uniforme de restos vegetais em toda a área da leira (0,25 m de espessura), em seguida, colocou-se uma camada de lixo orgânico $(0,15 \mathrm{~m}) \mathrm{e}$, posteriormente, outra camada de esterco de curral $(0,10 \mathrm{~m})$, pois, este material é mais pesado. Desta maneira, o material mostrou-se distribuído em camadas uniformes e sucessivas. Na parte superior da leira colocou-se uma camada de sobras de peneiramento do composto pré-processado.

Após a massa passar por 5 dias em ambiente aberto, em camadas alternadas de $1,5 \mathrm{~m}$ de altura e $5 \mathrm{~m}$ de comprimento, em uma fase chamada de Ativa (PEREIRA NETO, 1996), esta foi depositada sobre um túnel de ventilação natural. Este túnel é 
constituído de madeira e tela no formato de trapézio com dimensões de $5 \mathrm{~m}$ de comprimento, 0,60m de largura na base inferior e $0,40 \mathrm{~m}$ de largura na base superior e 0,60 m de altura, o túnel tem aberturas laterais para a aeração da massa.

Os dados das temperaturas ambientais e do composto, de umidade, de tempo de maturação e de granulometria foram anotados diariamente. As condições ambientais e as respectivas alterações a que o processo ficou sujeito se resumem na (tabela e figura 1). Observa-se que a temperatura do composto (que corresponde positivamente à atividade dos microorganismos decompositores) não sofre grandes influências das variações ambientais de temperatura e de pluviosidade.

Tabela 1: Pluviosidade, temperatura ambiente x Temperatura do composto (ação microbiana).

\begin{tabular}{|c|c|c|c|}
\hline Período & $\begin{array}{c}\text { Temp. do composto } \\
\left({ }^{\circ} \mathrm{C}\right)\end{array}$ & $\begin{array}{l}\text { Chuva no Período } \\
\qquad\left(\mathrm{mm}^{3}\right)\end{array}$ & $\begin{array}{l}\text { Temperatura do } \\
\text { ambiente }\left({ }^{\circ} \mathrm{C}\right)\end{array}$ \\
\hline $1^{\mathrm{a}}$ Semana & $54,4 \pm 2,2$ & $74 \pm 13$ & $23 \pm 4,5$ \\
\hline $2^{\mathrm{a}}$ Semana & $62 \pm 3,4$ & $18 \pm 14,3$ & $25 \pm 6,0$ \\
\hline $3^{\mathrm{a}}$ Semana & $56 \pm 5,9$ & $48 \pm 10$ & $22,7 \pm 3,4$ \\
\hline $4^{\mathrm{a}}$ Semana & $57 \pm 4,5$ & $44 \pm 2,2$ & $22,67,4$ \\
\hline $5^{\text {a }}$ Semana & $58 \pm 3,3$ & 0 & $18,3 \pm 2,3$ \\
\hline $6^{\mathrm{a}}$ Semana & $56 \pm 2,4$ & 0 & $19 \pm 4,5$ \\
\hline $7^{\mathrm{a}}$ Semana & $54 \pm 1,3$ & 0 & $20,5 \pm 3.4$ \\
\hline $8^{\mathrm{a}}$ Semana & $54 \pm 2,2$ & 0 & $20,5 \pm 5,6$ \\
\hline $9^{\mathrm{a}}$ Semana & $53 \pm 2,3$ & $13 \pm 12$ & $19 \pm 9,3$ \\
\hline $10^{\mathrm{a}}$ Semana & $51 \pm 3,1$ & 0 & $21,9 \pm 4,3$ \\
\hline $11^{\mathrm{a}}$ Semana & $49 \pm 4,7$ & 0 & $19,9 \pm 3,4$ \\
\hline $12^{\mathrm{a}}$ Semana & $48 \pm 9,0$ & 0 & $19,5 \pm 2,6$ \\
\hline $13^{\mathrm{a}}$ Semana & $48 \pm 5,5$ & 0 & $18,9 \pm 8,7$ \\
\hline 14 Semanas & $45 \pm 3,4$ & 0 & $17,5 \pm 6,9$ \\
\hline $15^{\mathrm{a}}$ Semana & $42 \pm 2,1$ & 0 & $18,4 \pm 4,8$ \\
\hline $16^{\mathrm{a}}$ Semana & $39 \pm 3,2$ & 0 & $20,1 \pm 3,5$ \\
\hline $17^{\mathrm{a}}$ Semana & $35 \pm 4,6$ & 0 & $19,7 \pm 7,8$ \\
\hline
\end{tabular}

Cada dado representa a média diária dos sete dias da semana 


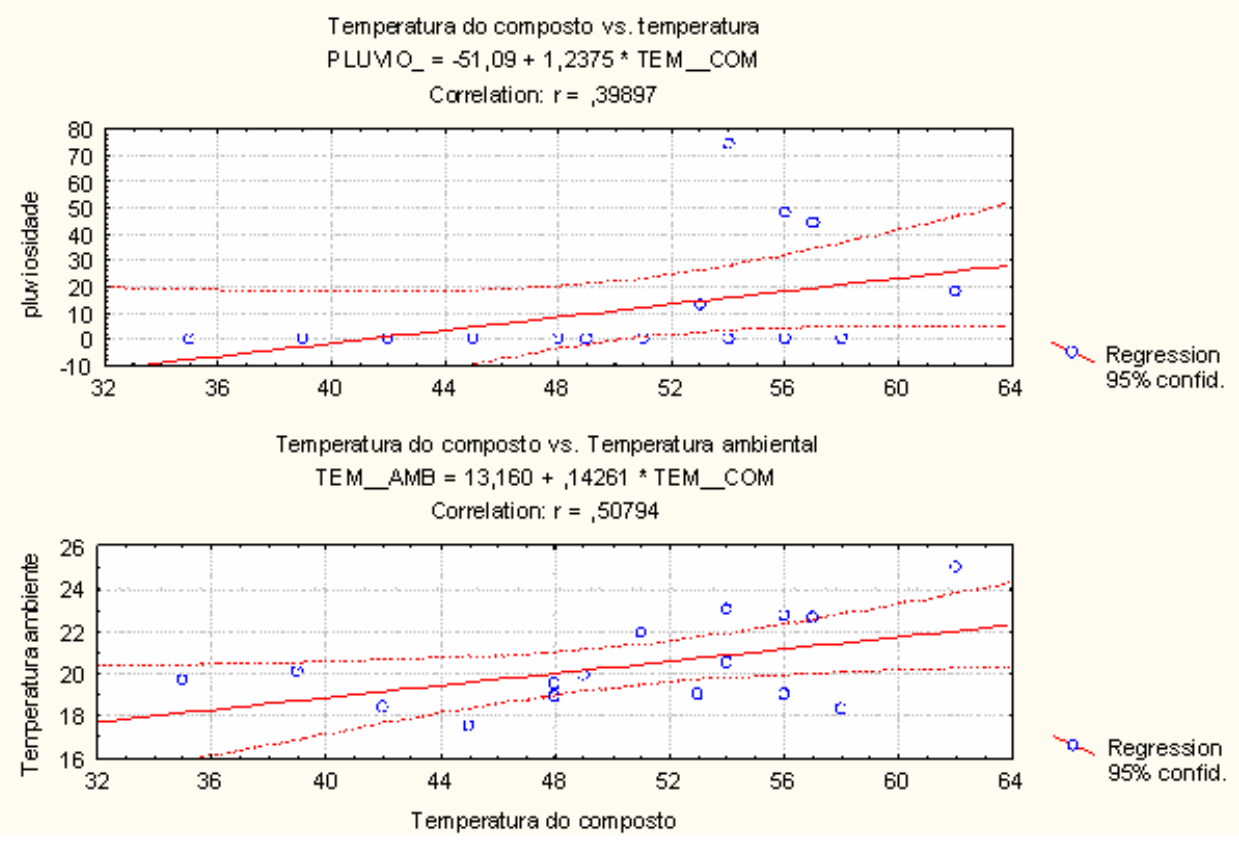

Figura 1. Relação entre temperatura do composto e dos fatores abióticos temperatura e pluviosidade (via Statistica V 0,5).

Ao fim do processo, foi retirada da leira uma amostra do composto orgânico para análise química (realizada pelo laboratório de análises de solo e fertilizantes orgânicos da Cooperativa de São Sebastião do Paraíso - COOPARAÍSO). A coleta foi feita aleatoriamente, retirando porções em vários pontos da massa de compostagem (5 porções de 500 gramas). Estas amostras foram misturadas e, da uma porção resultante, foram retirados 500 gramas que foi enviado ao Laboratório Regional de Fertilidade do Solo e Análise Foliar COOPARAÍSO. A análise foi realizada seguindo as técnicas da titulometria, fotometria, precipitação, espectrofotometria, calcinação, desidratação, potenciometria, além de cálculos para determinar fatores importantes em um composto orgânico como: Nitrogênio, fósforo, potássio, matéria orgânica, umidade, relação carbono/nitrogênio, $\mathrm{pH}$ e outros micronutrientes. O tamanho das partículas do composto não ultrapassou $5 \mathrm{~cm}$ (relativamente pequeno).

A composição química do produto final da compostagem não se diferenciou substancialmente dos produtos descritos em outras publicações envolvendo produtos orgânicos que não eram lixo (tabela 2) 
Tabela 2- Análise química do composto orgânico.

\begin{tabular}{|c|c|c|c|c|}
\hline Determinação & Extrator/Digestor & Técnica Analítica & Resultado & Unidade \\
\hline (N.Total) Nitrogênio & Micro Kjedal & Titulometria & 1,2 & $\%$ \\
\hline \multicolumn{5}{|l|}{ Amoniacal } \\
\hline (P2O5) Fósforo & Ácido Nitroclorídrico & Precipitação & 1,45 & $\%$ \\
\hline (K2O) Potássio & Água & Fotometria de chama & 0,90 & $\%$ \\
\hline (Ca) Cálcio & Nitroperclórico & Espectrofotometria & 1,12 & $\%$ \\
\hline (Mg) Magnésio & Nitroperclórico & Espectrofotometria & 0,37 & $\%$ \\
\hline (M.O.) Matéria Orgânica & Sem extrator & Calcinação & 15,39 & $\%$ \\
\hline Cinzas & Sem extrator & Cálculo & 84,61 & $\%$ \\
\hline Umidade & Sem extrator & Desidratação & 21,47 & $\%$ \\
\hline$(\mathrm{Cu})$ Cobre & Nitroperclórico & Espectrofotometria & 0,10 & $\mathrm{~g} / \mathrm{Kg}$ \\
\hline (Fe) Ferro & Nitroperclórico & Espectrofotometria & 13,80 & $\mathrm{~g} / \mathrm{Kg}$ \\
\hline (Mn) Manganês & Nitroperclórico & Espectrofotometria & 0,20 & $\mathrm{~g} / \mathrm{Kg}$ \\
\hline (Zn) Zinco & Nitroperclórico & Espectrofotometria & 0,20 & $\mathrm{~g} / \mathrm{Kg}$ \\
\hline (pH) potencial Hidrogênico & Água & Potenciometria & 6,80 & \\
\hline$(\mathrm{C} / \mathrm{N})$ Relação $\mathrm{C} / \mathrm{N}$ & Sem extrator & Cálculo & 7,12 & \\
\hline
\end{tabular}

- Análises realizadas pelo Laboratório Regional de Fertilidade do Solo e Análise Foliar COOPARAÍSO. A análise foi realizada seguindo as técnicas da titulometria, fotometria, precipitação, espectrofotometria, calcinação, desidratação, potenciometria, além de cálculos para determinar fatores importantes em um composto orgânico como: Nitrogênio, fósforo, potássio, matéria orgânica, umidade, relação carbono/nitrogênio, $\mathrm{pH}$ e outros micronutrientes.

\section{O adubo produzido pelos produtores rurais se mostrou muito eficaz}

Para verificar a viabilidade do produto como fertilizante, foi montado um experimento com 3 canteiros semeados simultaneamente, com diferentes tipos de substrato. Cada canteiro abrigava 15 repetições. No controle (Grupo 1), cada vaso foi preenchido com o substrato composto de terra vermelha peneirada (200g) e calcário dolomítico $(10 \mathrm{~g})$ para a correção do $\mathrm{pH}$. No Grupo 2, os vasos foram preenchidos com o substrato contendo $140 \mathrm{~g}$ de terra, $10 \mathrm{~g}$ de calcário dolomítico e $50 \mathrm{~g}$ de esterco de gado curtido. No Grupo 3, foram colocados em cada vaso $140 \mathrm{~g}$ de terra, $10 \mathrm{~g}$ de calcário dolomítico e $50 \mathrm{~g}$ de composto orgânico produzido pelo experimento. Estes canteiros receberam o mesmo manejo de irrigação. Todos os brotamentos foram observados diariamente e anotados cronologicamente. $\mathrm{O}$ grupo submetido à aplicação do fertilizante apresentou uma maior germinação das sementes: No Controle, após 6 dias estava 
completo o quadro de germinação das 15 sementes. No canteiro 2 (substrato + Esterco de vaca: a germinação se completou em 5 dias. No canteiro 3 (substrato + composto): as 15 sementes haviam germinado ao final do $3^{\circ}$ dia. Também, ficou evidente a eficiência do composto na retenção de água (o que não deve ser entendido como solo encharcado), auxiliando no processo de aceleração da germinação das sementes.

\section{Um bom programa a ser desenvolvido em comunidades rurais}

O desenvolvimento da agricultura sustentável e da segurança alimentar são metas urgentes deste novo milênio. Tanto em países desenvolvidos como nos em desenvolvimento, o setor agrícola tem uma variedade de papéis, tais como, ajudar a garantir a segurança alimentar, fornecer recursos para a subsistência e de rendimentos e fazê-los sem destruir o meio ambiente. Existem, portanto, indissoluvelmente, três componentes básicos para a sustentabilidade agrícola: o social, o econômico e o ambiental (SLIGH \& CHRISTMAN, 2007).

A atividade agro-ecológica relatada aqui deveria ser empregada por muitos outros produtores rurais da região - a transformação do lixo doméstico produzido em uma fazenda, em um composto fertilizante viável- pois além de ser viável, resolve o problema do lixo orgânico, transformando-o em adubo, gerando economia e ainda promovendo uma maior percepção do ambiente e uma conscientização ecológica. A estrutura proposta para a compostagem com aeração, que garantiu a oxidação necessária para a atividade microbiológica, foi de baixo-custo, pois foi construída com material descartado pela própria fazenda e permitiu que o agricultor economizasse mão-de-obra e ainda resolvesse o problema do lixo produzido no local.

O processo de produção do adubo aqui relatado contempla os principais temas importantes na ecologia global, pois ao retirar o lixo das casas, resolve um problema de saneamento e saúde pública, ao transformá-lo em adubo viável, sem resíduos químicos prejudiciais, se alia a temas como sustentabilidade e segurança alimentar. Segundo MALUF et al (1996) o objetivo da segurança alimentar implicaria combinar (a) ações assistenciais-compensatórias frente a questões emergenciais como a fome, com políticas de caráter estruturante visando assegurar (b) o acesso aos alimentos sem comprometer parcela substancial da renda familiar; (c) a disponibilidade de alimentos de qualidade, originados de formas produtivas eficientes, porém, não excludentes e sustentáveis e (d) divulgação de informações ao consumidor sobre práticas alimentares saudáveis e possíveis riscos à saúde, mediados pelo alimento. A ação deste projeto se 
aplica a este último item. Pois se reduziu os perigos da convivência com o lixo doméstico e conseguiu-se um produto adequado que garante a maior produção de alimentos saudáveis.

As características do produto resultante da decomposição do lixo doméstico foram satisfatórias, pois suas partículas tinham um tamanho relativamente pequeno (menores que $5 \mathrm{~cm}$ ), um bom resultado considerando que a massa de compostagem é formada por restos vegetais, como poda de grama, casca de frutas e verduras, restos de comida, esterco de gado e palha de arroz. Este tamanho de partícula propicia uma adequada degradação por parte dos microorganismos (aumenta a superfície de contato).

Aparentemente, com este mecanismo de compostagem, a temperatura do composto não foi muito influenciada pela temperatura do ambiente ou pela pluviosidade. É claro que se os fatores bióticos e abióticos fossem extremamente controlados, a produtividade e a qualidade do adubo orgânico seriam maiores, neste trabalho simulamos uma situação natural, onde todo o processo de compostagem foi mantido ao ar livre, sujeito, conseqüentemente, as intempéries da natureza do local (como seria mais prática a realização por produtores rurais). Tal fato contribuiu que a umidade da pilha de compostagem ficasse restringida a uma média de $60 \pm 5,2 \%$. Do ponto de vista teórico, o valor ideal para propiciar a degradação dos resíduos orgânicos é próximo a $100 \%$. Entretanto esta porcentagem mostrou-se adequada para o manejo do composto.

Segundo a análise química, a porcentagem de nitrogênio apresentada pelo experimento que foi de $1,2 \%$, dentro da margem considerada adequada por Alves (1998) que varia entre 1,0 a 1,5\% de nitrogênio total disponível para a planta. Os teores de fósforo foram mais altos do que os valores encontrados por TIBAU (1983) em compostos analisados, apesar dos percentuais elevados, contudo, a forma orgânica não é absorvível pela planta, pois é necessário, que ocorra a mineralização para ser absorvido pelos vegetais (COSTA et al., 1993). A porcentagem de potássio $(0,90 \%)$ está de acordo com os resultados de Pereira neto (1996). Segundo os valores mencionados na tabela 2, o composto orgânico disponibiliza aproximadamente $10 \mathrm{Kg}$ de $\mathrm{K}_{2} \mathrm{O}$ por tonelada aplicada ao solo. $\mathrm{O}$ valor de $\mathrm{pH}$ encontrado no composto também se enquadra na faixa considerada mais apropriada para a maioria das culturas (TEIXEIRA, 2002). O Magnésio, um nutriente que está relacionado com atividades fisiológicas importantes para a planta, tais como o transporte de fósforo, o aumento na absorção dos fertilizantes e no armazenamento deste elemento na semente (TEIXEIRA, 2002), apresentou 
concentração de 0,37\%. Em relação à matéria orgânica, os valores chegaram a 15,49\%. Este resultado difere dos de Nakagawa et al. (1992), que em compostos elaborados com casca de amendoim e capim napier e casca de amendoim com esterco bovino, apresentaram média de $24,7 \%$ de matéria orgânica, porém o material utilizado neste experimento é de mais fácil acesso na região do que os utilizados por estes autores em seus estudos. Ademais, um dos objetivos deste trabalho, é dar uma utilidade ao lixo orgânico.

Enfim, esta técnica é muito adequada para ser desenvolvida em comunidades rurais do Brasil, onde as condições ambientais são parecidas, desde que associadas à conscientização da população local. A resolução de problemas ambientais locais, orientada pragmaticamente a partir da perspectiva de uma atividade fim, pode produzir, como um passe de mágica, o mesmo efeito do 'desaparecimento' dos atores sociais e dos condicionantes que propiciaram o surgimento do problema ambiental tido como objeto didático de enfrentamento (REIGOTA, 2001).

\section{CONCLUSÃO}

Com este trabalho pode-se concluir que um projeto sócio-econômico e ambiental pode ser desenvolvido, dentro de uma comunidade rural, sem custo adicional e pode transformar um problema (lixo) em algo útil para o agricultor. A compostagem em leira estática com ventilação natural oferece bons resultados quanto ao nitrogênio, fósforo e potássio, que são os principais elementos necessários para o desenvolvimento da planta, tornando-se uma ótima opção para os produtores rurais, principalmente neste período em que o preço dos adubos químicos sofreu um acréscimo de $70 \%$ em relação aos anos anteriores.

\section{REFERÊNCIAS BIBLIOGRÁFICAS}

ALVES, W.L. Compostagem e vermicompostagem no tratamento de lixo urbano. $2^{\text {a }}$ Ed., Jaboticabal: Funep, 1998. 53p.

COSTA, M. B. B. da (Coord.). Adubação verde no Sul do Brasil. 2. ed. Rio de Janeiro: AS-PTA, 1993. 346 p.

CRAVO, M. S.; MURAOKA, T.; GINÉ, M. F. - Poluição e Qualidade Ambiental: Caracterização química de compostos de lixo urbano de algumas usinas brasileiras: Revista Brasileira de Ciências do Solo, Campinas, v.22, n.3, p. 5547 - 5553, 1998. 
GLENN, J.; N. GOLDSTEIN.. Food residuals composting in the U.S. BioCycle, 40:3036,1999

IBGE. Indicadores de Desenvolvimento Sustentável. Rio de Janeiro: IBGE, 2002

KIEHL, J.E. Fertilizantes orgânicos. Piracicaba: Agronômica Ceres, 1985. $492 \mathrm{p}$

MALUF, R. S.; MENEZES, F.; VALENTE, F. L. Contribuição ao Tema da Segurança Alimentar no Brasil.. Revista Cadernos de Debate, uma publicação do Núcleo de Estudos e Pesquisas em Alimentação da UNICAMP, Vol. IV: 66-88. 1996

Ministério da Agricultura, Pecuária e Abastecimento. Instrução Normativa $\mathrm{n}^{\mathrm{o}} 15$. Brasília: Diário Oficial da União; 2004.

NAKAGAWA, J.; BÜLL, L.T.; PROCHNOW, L.I.; VILLAS BOAS, R.L. Efeitos de compostos orgânicos na cultura do alface (Lactuca sativa L.). Série I. Científica, São Paulo, v.20, n.1, p.173-180, 1992.

PEREIRA NETO, J. T. \& CUNHA, W.G. Influência da Inoculação de Composto Orgânico Maturado no Período de Compostagem de Resíduos Orgânicos: in Congresso Brasileiro de Engenharia Sanitária e Ambiental, 17, 1995, Salvador: ANAIS: Salvador: 1995. $12 \mathrm{p}$.

PEREIRA NETO, J. T. - Manual de Compostagem: processo de baixo custo. Belo Horizonte: UNICEF, 56 p - 1996.

REIGOTA, Marcos. Verde cotidiano: O meio Ambiente em discussão. $2^{\circ}$ ed. RJ: DP\& A, 2001

REVISTA BRASILEIRA DE EDUCAÇAÕ AMBIENTAL. Rede Brasileira de Educação Ambiental. Brasília, 2004

SIKORA, L.J., \& SULLIVAN, D.M.. Case studies of municipal and on-farm composting in the United States.. In J. Power and W. Dick (ed.) Land application of agricultural, industrial, and municipal by-products. SSSA Book Ser. No. 6. SSSA, Madison, WI, p. 605-623, 2000.

SLIGH, M A. \& CHRISTMAN C. Organic agriculture and acess to food. International Conference Of Organic Agriculture And Food Segurity. Italy - 32 p, 2007. Disponível em ftp://ftp.fao.org/paia/organicag/ofs/OFS-2007-2.pdf. acessado em 05/05/2009

STEINER, Rudolf. Fundamentos da Agricultura Biodinâmica. Verlag Dornach, 1924; tradução de Gerard Banwart. São Paulo: Antroposófica, 2000.

TAIZ, L. E ZEIGER, E. - Fisiologia Vegetal. Porto Alegre: Artmed, 2004.

TEIXEIRA, L. B.; GERMANO, V. L. C.; OLIVEIRA, R. F. DE; FURLAN JÚNIOR J. Processo de compostagem, a partir de lixo orgânico urbano, em leira estática com ventilação natural. Ministério da Agricultura, Pecuária e Abastecimento. Embrapa Circular técnica. Belém, PA - Outubro, 2004. 
TEIXEIRA, L.B.; OLIVEIRA, R.F. DE; FURLAN JÚNIOR, J.; CHENG, S.S. Comparação de composto orgânico de Barcarena com adubos orgânicos tradicionais quanto às propriedades químicas. Belém: Embrapa Amazônia Oriental, 2002.

TIBAU, A. O. Matéria orgânica e fertilidade do solo. 2ed. São Paulo: Nobel, 1983 193.p.30- 127.

TOUART, A.P. 1999. Investing upfront in a compost factory. Biocycle 40:31-33. 